\title{
Is first trimester body mass index of antenatal mothers associated with selected feto-maternal outcomes?
}

\section{Chanchal Arora, Smitha Thadathil*, Rejani R., Punita A. Sharma}

College of Nursing, Armed Forces Medical College, Pune, Maharashtra, India

Received: 04 January 2019

Accepted: 05 February 2019

\section{*Correspondence:}

Lt. Col. Smitha Thadathil,

E-mail: smithathdathil75@gmail.com

Copyright: () the author(s), publisher and licensee Medip Academy. This is an open-access article distributed under the terms of the Creative Commons Attribution Non-Commercial License, which permits unrestricted non-commercial use, distribution, and reproduction in any medium, provided the original work is properly cited.

\section{ABSTRACT}

Background: Mothers are the creators and sustainers of progeny. The health and wellbeing of children is intimately linked with the health, nutrition, education and well-being of their mothers because she is both the seed as well as the soil where in the baby is nurtured for 9 months. Hence the present study was conducted to determine the association between first trimester body mass index (BMI) of antenatal mothers with the mode of delivery, birth weight and APGAR scores of new born babies at birth in a tertiary care hospital.

Methods: A cross-sectional study was conducted amongst 115 antenatal mothers who reported to the Labor room in a tertiary care hospital of Pune during the period of Nov. 2017 to Feb. 2018, to determine the association between first trimester body mass index (BMI) of antenatal mothers with the mode of delivery, birth weight and APGAR scores of new born babies.

Results: The findings were suggestive of increased odds of APGAR of $<7$ at 1 min of birth among new born babies born to the study participants of low BMI group as compared to the new born babies born to the high BMI group; Increased odds of birth weight of $>3.5 \mathrm{~kg}$ and gestational weight gain of $>14 \mathrm{~kg}$ and greater odds of complications among new born babies born to the study participants of high BMI group than the new born babies born to the low BMI group.

Conclusions: The study concluded that birth weight of the new born babies shows a clinically significant increasing trend in association with the increasing first trimester BMI of their mothers.

Keywords: APGAR score, Birth weight, Body mass index, Feto- maternal outcomes, Obesity

\section{INTRODUCTION}

Mothers are the creators and sustainers of progeny. The health and wellbeing of children is intimately linked with the health, nutrition, education and well-being of their mothers because she is both the seed as well as the soil where in the baby is nurtured for 9 months. ${ }^{1}$

In 2009, the Institute of Medicine (IOM), USA published revised GWG guidelines based on pre-pregnancy ranges for underweight, normal weight, overweight, and obese women. $^{2}$ These recommendations were based on American women, thus its generalizability to other populations is unclear. The IOM later published a commentary acknowledging that their recommendations were based primarily on the basis of primigravida mothers of high social status and those with no physical activity. $^{3}$

Some recent studies from Asia have concluded that IOM guidelines are suitable for the Asian population, whereas others have reported that GWG among Asians is different from what has been recommended by the IOM. ${ }^{4}$ There are very few studies from India that have looked at the applicability of the IOM guidelines in pregnant women, mainly because the BMI classification for Asians is 
different from the World Health Organization BMI cut offs recommended for the west. ${ }^{5}$ Maternal BMI is one of the predictor of nutritional status of pregnant mother. The normal growth and development of the fetus is dependent on pre-pregnant maternal weight to a great extent, among many other factors.

Maternal nutritional intake and weight during pregnancy are two modifiable factors which influence fetal outcome. Recent studies have reported that maternal pre-pregnancy BMI is associated with birth weight of the infant. Obesity during pregnancy has both short- and long-term adverse consequences for both mother and child. ${ }^{6}$

The effect of maternal underweight on obstetric performance is less clear. While some researchers have found increased incidences of pre term delivery, low birth weight and increased perinatal loss in these women. ${ }^{7}$ Others have also reported a protective effect of maternal underweight on certain pregnancy complications and interventions. $^{8}$

Indeed a low body mass index and suboptimal weight gain during pregnancy are long recognized risk factors for the delivery of babies too small for gestational age. ${ }^{9}$

The objectives of the present study was to observe the association between first trimester body mass index of antenatal mothers with the mode of delivery, birth weight and APGAR scores of new born babies at birth in a tertiary care hospital.

\section{METHODS}

A cross-sectional study was conducted at maternity units of the selected tertiary care hospital in Urban Pune, Maharashtra during the period of Nov. 2017 to Feb. 2018 amongst 115 antenatal mothers, selected using purposive sampling technique.

\section{Inclusion criteria}

- Antenatal women aged between 18-35 years with singlet on pregnancy, gestational age between $37-42$ weeks, and reporting to labour room for delivery with first trimester weight recorded in antenatal case record.

\section{Exclusion criteria}

- Women with diabetes, cardiac, renal or endocrinal dysfunctions, $\mathrm{Rh}$ isoimmunization, multi fetal gestation and post LSCS pregnancies.

Ethical clearance was taken from the Institutional Ethical Committee. After written informed consent, data was collected with the help of a structured tool. A pilot study was done to try out the tool and necessary amendments were made accordingly. Based on the first trimester BMI in the antenatal records, the women were classified into the corresponding BMI Groups.

Data analysis: All recorded data were entered in MS Excel sheet and analyzed in the form of percentage and proportions whenever necessary. Chi-square test was used as a test of significance. For all statistical test applied, $\quad \mathrm{p}<0.05$ was considered as statistically significant.

\section{RESULTS}

The selected women were followed up for the mode of delivery, APGAR score and birth weight of the baby. As the samples in the overweight group were very less, therefore the overweight and obese group were merged into a single group as overweight (as shown in Table 1a and $1 \mathrm{~b})$.

Table 1a: WHO Asia Pacific criteria for BMI used and Institute of Medicine (IOM) recommendations for weight gain in pregnancy. ${ }^{4}$

\begin{tabular}{|l|l|l|} 
Weight gain & $\begin{array}{l}\text { WHO Asia } \\
\text { Pacific criteria- } \\
\text { BMI (kg/m²) }\end{array}$ & $\begin{array}{l}\text { IOM } \\
\text { recommended } \\
\text { weight gain (in } \mathrm{kg})\end{array}$ \\
\hline Under weight & Less than 18.5 & $12-18$ \\
\hline Normal weight & $18.5-22.9$ & $11.5-16$ \\
\hline Over weight & $23-24.9$ & $7-11.5$ \\
\hline Obese & More than 25 & $5-9$ \\
\hline
\end{tabular}

Table 1b: First trimester BMI groups in the present study.

\begin{tabular}{|l|l|l|}
\hline Group No. & BMI category & BMI \\
\hline Group-1 & Low BMI & $<18.5 \mathrm{~kg} / \mathrm{m}^{2}$ \\
\hline Group-2 & Normal BMI & $18.5-22.9 \mathrm{~kg} / \mathrm{m}^{2}$ \\
\hline Group-3 & High BMI & $>23 \mathrm{~kg} / \mathrm{m}^{2}$ \\
\hline
\end{tabular}

It was seen from Table 2 that among the 115 women selected for the study, majority $(45 \%)$ belonged to the age group of 19-25 years.

The important parameter that has come to the notice is that, while $42.6 \%$ of the participants had a normal First Trimester BMI, an alarming $22.6 \%$ of the participants fell into the overweight category with the First Trimester BMI of 25 and above. It was seen from Table 3 that amongst the Low BMI group, out of 26 women,19 underwent vaginal delivery, 4 underwent LSCS and 3 underwent Vacuum extraction. In the high BMI group 26 women $(65 \%)$ underwent vaginal delivery, 13 women (33\%) underwent LSCS while 4 underwent vacuum extraction. 
Table 2: Distribution of the subjects according to the selected socio-demographic characteristics $(n=115)$.

\begin{tabular}{|c|c|c|c|}
\hline \multicolumn{2}{|c|}{ Sociodemographic characteristics } & Frequency & $\%$ \\
\hline \multirow{3}{*}{ Age (in years) } & $19-25$ & 52 & 45.2 \\
\hline & $26-30$ & 46 & 40.0 \\
\hline & $>30$ & 17 & 14.8 \\
\hline \multirow{5}{*}{ Education level } & Illiterate & 03 & 02.6 \\
\hline & Up to secondary & 36 & 31.3 \\
\hline & Higher secondary & 28 & 24.3 \\
\hline & Graduate & 35 & 30.4 \\
\hline & Post graduate & 13 & 11.3 \\
\hline \multirow{3}{*}{ Dietary Preferences } & Vegetarian & 22 & 19.1 \\
\hline & Egg vegetarian & 01 & 0.9 \\
\hline & Non-vegetarian & 92 & 80.0 \\
\hline \multirow{4}{*}{ First trimester BMI (in $\mathrm{kg} / \mathrm{m}^{2}$ ) } & $<18.5$ & 26 & 22.6 \\
\hline & $18.5-22.99$ & 49 & 42.6 \\
\hline & $23-24.99$ & 14 & 12.2 \\
\hline & 25 and above & 26 & 22.6 \\
\hline
\end{tabular}

Table 3: Association between mode of delivery and first trimester BMI in study group (n=115).

\begin{tabular}{|l|l|l|l|l|}
\hline Mode of delivery & BMI $<\mathbf{1 8 . 5} \mathrm{kg} / \mathbf{m}^{2}$ & BMI $\mathbf{1 8 . 5}-\mathbf{2 2 . 9 9} \mathrm{kg} / \mathrm{m}^{2}$ & BMI $>\mathbf{2 3} \mathrm{kg} / \mathrm{m}^{2}$ & Total $(\%)$ \\
\hline Vaginal & 19 & 33 & 26 & $\mathbf{7 8}(67.9)$ \\
\hline Vacuum & 03 & 03 & 01 & $07(5.9)$ \\
\hline Forceps & 00 & 00 & 00 & $00(0.0)$ \\
\hline LSCS & 04 & 13 & 13 & $30(26.2)$ \\
\hline Total & 26 & 49 & 40 & $115(100)$ \\
\hline
\end{tabular}

$(\mathrm{x} 2=5.96, \mathrm{p}=0.43)$

Although the Chi Square value was not statistically significant but clinically there is preponderance of vaginal delivery in the Low BMI group, higher preponderance towards LSCS in the High BMI group and comparatively increased risk of Vacuum extraction in the Low BMI group.

Figure 1 illustrates that in the study $87.8 \%$ new born babies had a normal APGAR Score of $>7$ and a mere $12.2 \%$ new born babies had an APGAR Score of $<7$ at 1 min of birth.

The association between APGAR score at 1 min of birth and first trimester BMI wasn't statistically significant but clinically a higher incidence of Low APGAR scores at 1 min of birth was seen among new born babies born to Low BMI group women (15.4\%) compared to normal and high BMI group (14.3\%), and (7.5\%).

Figure 2 illustrates that majority of the new born babies 111 had normal APGAR Scores, while 4 new born babies continued to have APGAR Score of $<7$ even after 5 minutes of birth and required active intervention.

Clinically a higher incidence of Low APGAR scores after 5 mins of birth was seen among new born babies born to Low BMI group women compared to Normal BMI and High BMI group women.

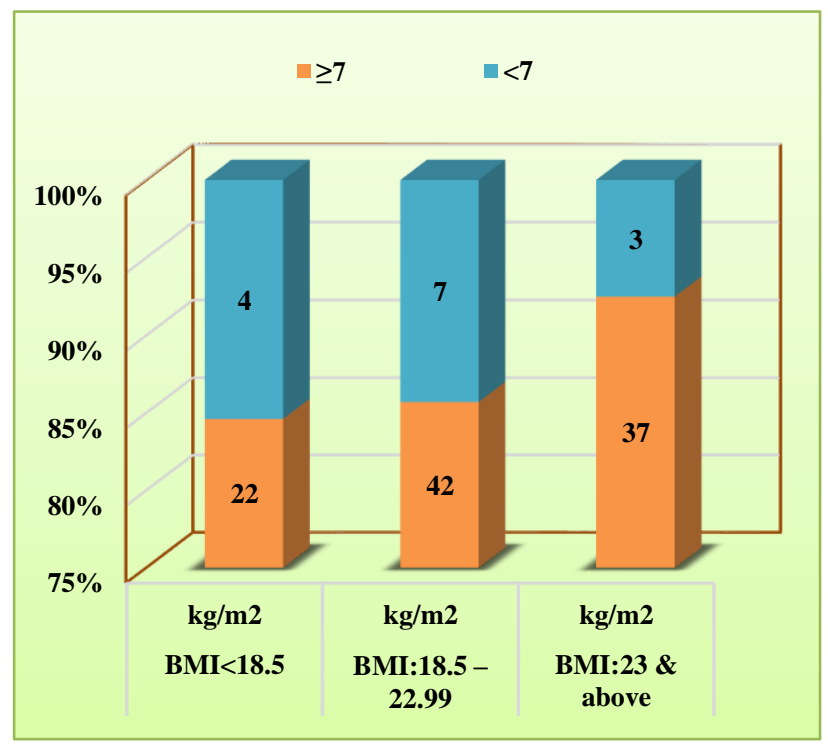

Figure 1: Association between APGAR scores of new born babies at 1 minute of birth and first trimester BMI of their mothers.

It was observed from Table 4 that the mean birth weight and SD of New born babies born to the study participants in the low BMI group, normal BMI group and high BMI group was $2.84 \mathrm{~kg}+0.337,2.95 \mathrm{~kg}+0.481$ and $3.04 \mathrm{~kg}$ +0.462 , respectively. Clinically, the birth weight of the 
new born babies shows an increasing trend in association with the increasing first trimester BMI of their mothers.

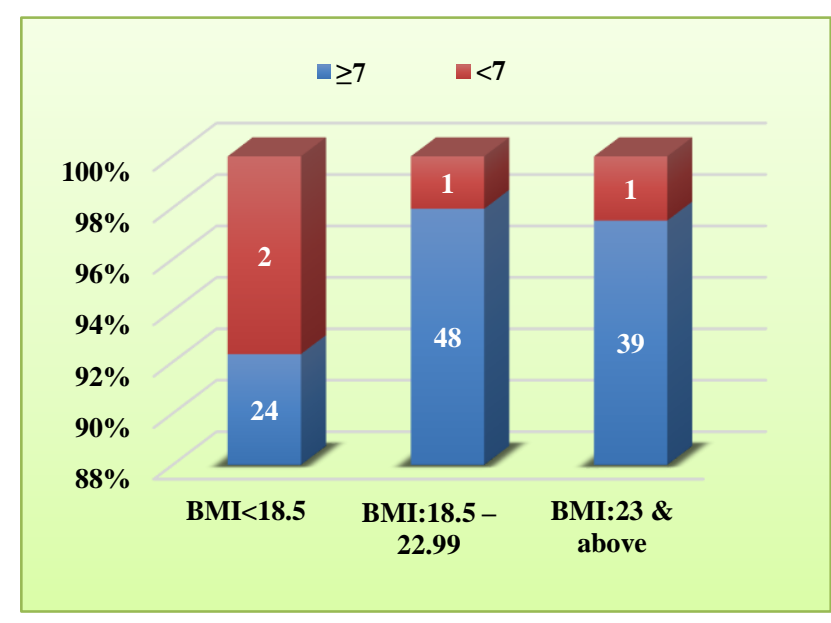

Figure 2: Association between APGAR scores of new born babies at 5 minutes of birth and first trimester BMI of their mothers.

Table 4: Comparison of birth weight of new born babies according to first trimester BMI of their mothers among the study participants $(n=115)$.

\begin{tabular}{|c|c|c|c|c|c|}
\hline \multirow[t]{2}{*}{ BMI $\left(\mathrm{kg} / \mathrm{m}^{2}\right)$} & \multirow[t]{2}{*}{ F } & \multicolumn{2}{|c|}{$\begin{array}{l}\text { First trimester } \\
\text { birth weight } \\
\text { (in kg) }\end{array}$} & \multirow[t]{2}{*}{$\begin{array}{l}\text { F- } \\
\text { value }\end{array}$} & \multirow[t]{2}{*}{$\begin{array}{l}\text { P- } \\
\text { value }\end{array}$} \\
\hline & & Mean & SD & & \\
\hline$<18.5$ & 26 & 2.84 & 0.337 & \multirow{3}{*}{1.74} & \multirow{3}{*}{0.18} \\
\hline $18.5-22.99$ & 49 & 2.95 & 0.481 & & \\
\hline 23 and above & 40 & 3.04 & 0.462 & & \\
\hline
\end{tabular}

F:Frequency

\section{DISCUSSION}

In the present study, the incidence of underweight was $(22.6 \%)$ and obesity was $(22.6 \%)$, these findings corresponds to the National Statistics as per NFHS 2016 , i.e., $22.9 \%$ and $20.7 \%$ respectively. 10 The mean BMI of the study population was $22.14 \pm 4.26 \mathrm{~kg} / \mathrm{m}^{2}$. The maximum gestational weight gain was $23 \mathrm{~kg}$ and minimum $1 \mathrm{~kg}$, while the mean weight gain was $10.5 \mathrm{~kg}$ with a SD of $\pm 4.3 \mathrm{~kg}$. The study participants in the high BMI group had greater odds of having a gestational weight gain of $>14 \mathrm{~kg}$ \{OR1.81 (0.70-4.69) $\}$ as compared to study participants in the low BMI group. There was a clinically significant trend of preponderance of vaginal delivery in the low BMI group and higher preponderance towards LSCS in the high BMI group, along with an increased risk of vacuum extraction in the low BMI group. The odds of LSCS in the high BMI group at a CI of $95 \%$ is higher $\{2.06\}$ compared to the low BMI group $\{0.53\}$. The findings were similar to a study conducted by Sebire NJ et al, in which an increased risk for cesarean delivery (OR- 2.3) and birth weight above 4,000 gm (OR3.9) was reported. ${ }^{11}$ Another study by Dietz PM revealed that incidence of LSCS increased with increased pre- pregnancy BMI from $14.3 \%$ for low BMI to $42.6 \%$ for morbidly obese women. Similar results were also reported by Vahratian A. ${ }^{12,13}$ Study by Murthy OK et al also reported a statistically significant increased rate of LSCS, among high BMI group when compared to normal BMI group. ${ }^{14}$ In the present study, the association between the APGAR score at 1 minute of birth and first trimester BMI was not statistically significant. But a higher incidence of low APGAR score at 1 min of birth was observed among new born babies born to low BMI group women $(15.4 \%)$ compared to normal BMI group women $(14.3 \%)$ and high BMI group women (7.5\%). Similarly, the association between the APGAR score after 5 min of birth was also not statistically significant, but a higher incidence of low APGAR score after 5 mins of birth was seen among new born babies born to low BMI group women $(7.6 \%)$ compared to normal BMI group $(2.0 \%)$ and high BMI group $(2.5 \%)$.

The new born babies born to the study participants of low BMI group have a slightly higher risk of an APGAR of $<7$ at birth $\{$ OR 1.09\} as compared to the new born babies born to those of high BMI group $\{$ OR 0.49 \}. A meta- analysis of 11 cohort studies conducted by Zhu T et al showed significant trends for APGAR score $<7$ at 5 minutes: overweight OR 1.13; (1.08-1.20), obese OR $1.40 ;(1.27-1.54)$, and very obese (OR 1.71; (1.55-1.89). The pooled analysis revealed that maternal overweight or obesity increased the risk for APGAR score $<7$ at 1 minute. ${ }^{15}$ The study also brought out some incidental findings related to the adverse perinatal outcomes among the study participants. The seven study participants had peri-partum complications like atonic/traumatic PPH, retention of placenta requiring manual removal of the placenta and majority were among the high BMI group.5 Among the study participants who underwent vaginal delivery, 12 sustained perineal tears of varying degrees, requiring surgical repair-2 first degree, 7 second degree, 2 third degree and 01 cervical tear. Out of which 5 subjects were from the high BMI group. Moreover, 6 subjects developed hypertensive disorders of pregnancy, all from the high BMI group. Women who underwent infertility treatment were the only women who had undergone preconceptional counselling; the remaining $99.9 \%$ study participants did not attend any form of pre-conceptional counselling. Majority of the study participants 67 reported in spontaneous labor, while 48 underwent induction of labor. In the low BMI group, only 7 out of 26 i.e. $27 \%$ needed to be induced whereas in the high BMI group, 23 out of 40 i.e. $47.9 \%$ were induced. There by indicating that the women with high first trimester BMI are more predisposed for induction of labour as compared to the women with low first trimester BMI.

\section{CONCLUSION}

The present study concluded that the birth weight of the new born babies shows a clinically significant increasing trend in association with the increasing first trimester BMI of their mothers. It was also seen that clinically a 
higher incidence of low APGAR scores after 5 mins of birth was seen among new born babies born to low BMI group women compared to normal BMI and high BMI group women. As far as mode of delivery is concerned, there was preponderance of vaginal delivery in the low BMI group, higher preponderance towards LSCS in the high BMI group and comparatively increased risk of vacuum extraction in the low BMI group.

\section{Recommendations}

A prospective cohort study can be done using appropriate time scale. More studies can be done on factors affecting overweight and obesity in pregnancy, gestational weight gain and its effect on the maternal and fetal outcome can also be studied. Similar studies can be done with larger sample size. Whether being underweight in pregnancy is protective for perinatal complications can be assessed. More stress should be laid on pre-conceptional counseling and preventive health with emphasis on maintaining normal BMI at the time of conception and BMI appropriate gestational weight gain.

Funding: No funding sources Conflict of interest: None declared

Ethical approval: The study was approved by the Institutional Ethics Committee

\section{REFERENCES}

1. Singh M. Care of the new born. $15^{\text {th }}$ ed. 2017. Sagar Publications; New Delhi: 2017;2-3

2. Institute of Medicine (US) Committee on Nutritional Status during Pregnancy and Lactation. Nutrition during pregnancy. Washington (DC): National Academies Press (US), 2009.

3. Rasmussen KM, Abrams B, Bodnar LM, Butte NF, Catalano PM, Maria Siega-Riz A. Recommendations for weight gain during pregnancy in the context of the obesity epidemic. Obstet Gynecol. 2010;116(5):1191-95.

4. Who EC. Appropriate body-mass index for Asian populations and its implications for policy and intervention strategies. Lancet (London, England). 2004;363(9403):157.

5. Radhakrishnan U, Kolar G, Nirmalan PK. Crosssectional study of gestational weight gain and perinatal outcomes in pregnant women at a tertiary care center in Southern India. J Obstet Gynaecol Res 2014;40(1):25-31.

6. Dasgupta A, Harichandrakumar KT, Habeebullah S. Pregnancy outcome among obese Indians-a prospective cohort study in a tertiary Care Centre in South India. Int J Sci Study. 2014;2(2):13-8.

7. World Health Organization. Technical Report Series on Maternal Prepregnant Weight and Its Effects. WHO: Geneva, Switzerland, 2000.

8. Razak F, Finley EJ, Subramaniam SV. Maternal underweight and child growth and development. Lancet. 2013;381(9867):626-7.

9. Zodpey S, Bangdiwala S, Niswade A, Ughade S. Neonatal morbidity and mortality in tribal and rural communities in central India. Indian J Community Med. 2011;36(2):150-58.

10. National Family Health Survey (NFHS-4) India, 2016. Available at: http://rchiips.org/NFHS/factsheet.shtml

11. Sebire NJ, Jolly M, Harris JP, Wadsworth J, Joffe M, Beard RW, et al. Maternal obesity and pregnancy outcome: a study of 287,213 pregnancies in London. Inter J Obes Relat Metabol Disord. 2001;25(8):117582.

12. Deitz PM. Population based assessment of the risk of primary caesarean delivery due to excess prepregnancy weight in nulliparous women. Maternal Child Health J. 2005;9(3):237-44.

13. Vahratian A. Maternal pre-pregnancy over weight and obesity and risk for primary caesarean delivery. Ann epidemiol 2005;15(7):467-74.

14. Murthy OK, Dhananjaya BS, Girish BL, Swathi P. A study of body mass index in pregnancy and its correlation with maternal and perinatal outcome. Indian J Obstet Gynecol Res. 2017;4(4):359-363

15. Zhu T, Tang J, Zhao F, Qu F, Dezhi. Association between maternal obesity and offspring Apgar score or cord pH: a systematic review and meta-analysis. Scientific Reports. 2015;5:1838-46.

Cite this article as: Arora $\mathrm{C}$, Thadathil S, Rejani R, Sharma PA. Is first trimester body mass index of antenatal mothers associated with selected fetomaternal outcomes? Int J Reprod Contracept Obstet Gynecol 2019;8:1030-4. 